\title{
Palladium-Catalyzed Asymmetric Formal [3+2] Cycloaddition
}

Metal-Catalyzed

Asymmetric

Synthesis and

Stereoselective

Reactions

\section{Key words}

palladium

Trost ligand

vinylcyclopropanes<smiles>C=CC1CC1(OCC)C(C)(C)C</smiles><smiles>CC1(C)OC(=O)C(=CP)C(=O)O1</smiles>

$( \pm)-1$
$\mathrm{Pd}_{2} \mathrm{dba}_{3} \cdot \mathrm{CHCl}_{3}(2-2.5 \mathrm{~mol} \%)$ (R,R)-ligand (6-7.5 mol\%)

dioxane or PhMe, r.t., $16 \mathrm{~h}$ (0.1-0.2 mmol scale)<smiles>[2H]C=C1N=C(c2ccccc2)OC1=O</smiles>

(1.3 equiv)

$E W G=$ ester

$\mathrm{R}=\mathrm{Ar}$, alkenyl, alkynyl, Alk

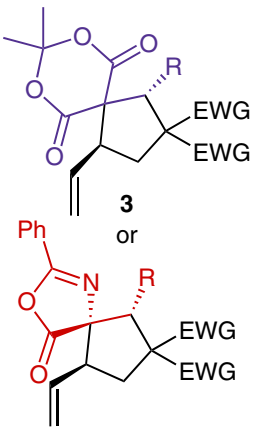

$32-87 \%$ yield dr from 3:1 to $>19: 1$ 63-99\% ee 28 examples formal [3+2] cycloaddition

cyclopentanes
Significance: A palladium-catalyzed asymmetric formal [3+2] cycloaddition of vinylcyclopropanes to electron-poor olefins is reported using the Trost ligand. The developed method can access highly substituted cyclopentanes with high diastereoand enantioselectivity with moderate to high yield.
Comment: As the vinylcyclopropanes 1 used are racemic, the authors propose that the reaction occurs under Curtin-Hammett conditions for this stereo-convergent reaction. Notably, the effects of $\pi-\sigma-\pi$ interconversion and the reversibility of the conjugate addition establish pre-equilibria of diastereomeric reactive intermediates $\mathbf{4}$ and $\mathbf{5}$, consequently favoring the formation of $\mathbf{3}$. 